\title{
BIOCHEMISTRY AND MOLECULAR BIOLOGY OF WAX PRODUCTION IN PLANTS
}

\section{Dusty Post-Beittenmiller}

Plant Biology Division, The Samuel Roberts Noble Foundation, Ardmore, Oklahoma 73402-2180

KEY WORDS: very long chain fatty acid elongation, glossy, elongase, condensing enzme, cuticular lipids

\begin{abstract}
The aerial surfaces of plants are covered with a wax layer that is primarily a waterproof barrier but that also provides protection against environmental stresses. The ubiquitous presence of cuticular wax is testimony to its essential function. Genetic and environmental factors influence wax quantity and composition, which suggests that it is an actively regulated process. The basic biochemistry of wax production has been elucidated over the past three decades; however, we still know very little about its regulation. This review presents a discussion along with new perspectives on the regulatory aspects of wax biosynthesis. Among the topics discussed are the partitioning of fatty acid precursors into wax biosynthesis and the elongation of fatty acids with particular emphasis on the nature of the acyl primer, and the role of ATP in fatty acid elongation. The recent cloning of wax biosynthetic genes and the transport of wax to plant surfaces are also discussed.
\end{abstract}

\section{CONTENTS}

INTRODUCTION

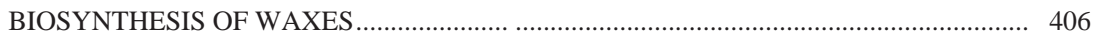

Composition of Plant Waxes .................................................................................. 406

De Novo Synthesis and Very Long Chain Fatty Acid Elongation .................................. 409

Multiple Elongation Systems ................................................................................ 410

BRANCH POINTS WITH OTHER LIPID BIOSYNTHETIC PATHWAYS....................... 413

Termination of Plastidial Fatty Acid Biosynthesis ...................................................... 414

What Are the Substrates for Elongase Condensing Enzymes? ........................................ 415 
Partitioning Between Wax and Cutin or Suberin ....................................................... 417

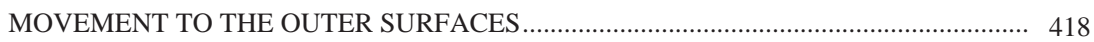

GLOSSY MUTANTS AND THE CLONING OF WAX-RELATED GENES …................... 419

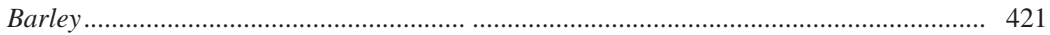

Maize and Sorghum …….................................................................................... 422

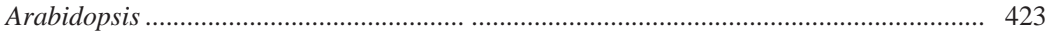

Tagging and Walking .......................................................................................... 424

Expressed Sequence Tags ................................................................................. 425

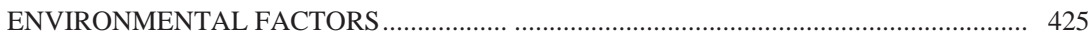

CONCLUSIONS AND FUTURE PROSPECTS …...................................................................... 425

\section{INTRODUCTION}

Waxes are the waterproofing component of the plant cuticle and are therefore essential for life in an aerial environment. They are embedded within cutin or suberin polymers and continue as an amorphous layer on the outer surface of the plant. In many plants, epicuticular wax crystalline structures overlay this layer, which gives the plant surface a glaucous or gray appearance. Plants deficient or altered in surface waxes appear shiny, glossy, or bloomless. This distinct and easily observed phenotype has been widely used in the isolation of mutants defective in wax production.

The cuticle provides the first line of defense between the plant and its environment; the cuticular waxes shed rainwater from the plant surface and limit nonstomatal water loss. In addition, waxes may protect plants from bacterial and fungal pathogens (52) and play a role in plant-insect interactions (26). Its hydrophobicity makes wax a good solvent for organic pollutants and impedes the uptake of aqueous foliar sprays without the addition of surfactants. In addition, the reflective nature of waxes offers some protection against damaging UV radiation.

Several excellent reviews over the past fifteen years have covered wax biosynthesis and composition, wax-deficient mutants, and wax function (19, 100, 100a). Therefore, this review focuses primarily on recent developments and their importance to our understanding of plant wax biosynthesis and its regulation. Emphasis is on the major wax biosynthetic pathways (studied most extensively by biochemical and molecular biological approaches) : decarbonylation, acyl-reduction, and $\beta$-ketoacyl elongation.

\section{BIOSYNTHESIS OF WAXES}

\section{Composition of Plant Waxes}

By definition, cuticular waxes are the hydrophobic compounds on the surface of the plant that are removed by a brief immersion in an organic solvent such as chloroform or hexane. They are complex mixtures of primarily very long chain (VLC, >C18) fatty acids, hydrocarbons, alcohols, aldehydes, ketones, 
esters, triterpenes, sterols, and flavonoids $(51,105)$. The proportions of the major classes vary among plant species (Table 1). For example, alkanes and ketones are major components of leek leaf, Arabidopsis stem, and Brassica leaf waxes but are very low or undetectable in barley and maize leaves. Peanut and alfalfa are rich in alkanes but have no ketones. The major components in alfalfa leaf wax are primary alcohols, compared with peanut leaf, in which the major wax components are fatty acids. In Arabidopsis, the proportion of ketones in the leaf wax is 30 -fold lower than the proportion of ketones in the stem wax.

Each lipid class of the cuticular wax may be present as a homologous series, or one particular chain length may predominate. When the major lipid class has a predominating homologue, characteristic wax crystals form on the plant's aerial surfaces. The shape and appearance of these crystals are due to the physical-chemical properties of the wax composition. For example, lobed plates are associated with a high proportion of the $\mathrm{C} 24$ species in the primary alcohols, which is the major class of cuticular wax on Quercus robur (oak) leaves (33). Long thin tubes are characteristic of large amounts of $\beta$-diketones on Hordeum vulgare (barley) lemma (100), and transversally ridged rodlets are associated with high levels of hentriacontan-16-one on leaf surfaces of members of the subclass Magnoliidae (33). There are also reports of similar crystalline structures from differing compositions (68).

Table 1 Major epicuticular lipid classes among several plant species

\begin{tabular}{|c|c|c|c|c|c|c|c|c|}
\hline Classes & Leek $^{1}$ & Barley $^{2}$ & Maize $^{3}$ & $\begin{array}{c}\text { Arabidop- } \\
\text { sis }{ }^{4} \text { stem }\end{array}$ & $\begin{array}{c}\text { Arabidop- } \\
\text { sis }^{5} \text { leaf }\end{array}$ & $\begin{array}{l}\text { Bras- } \\
\text { sica }^{6}\end{array}$ & Peanut $^{7}$ & Alfalfa $^{8}$ \\
\hline Fatty acids & $6.4^{9}$ & 10.3 & $\operatorname{tr}^{10}$ & 3.2 & 3.6 & 1.9 & 38.1 & N.D. ${ }^{11}$ \\
\hline Aldehydes & 10.8 & 1.7 & 20.0 & 5.9 & 2.1 & 3.9 & 2.4 & 20.5 \\
\hline Alkanes & 31.0 & $\operatorname{tr}$ & 1 & 38.0 & 73.6 & 40.3 & 35.7 & 20.0 \\
\hline $2^{\circ}$ alcohols & N.D. & N.D. & N.D. & 10.3 & 0.7 & 11.9 & N.D. & N.D. \\
\hline Ketones & 51.8 & N.D. & N.D. & 30.4 & 1.2 & 36.1 & N.D. & N.D. \\
\hline $1^{\circ}$ alcohols & N.D. & 83.0 & 63.0 & 11.8 & 18.5 & 1.9 & 23.8 & 48.4 \\
\hline Wax esters & N.D. & 4.7 & 16.0 & 0.8 & 0.2 & 3.9 & N.D. & 11.0 \\
\hline
\end{tabular}

1. Allium porrum, Y Rhee \& D Post-Beittenmiller, unpublished manuscript.

2. Hordeum vulgare, primary leaves (32a).

3. Zea mays seedlings (6).

4. A. thaliana (Landsberg erecta, ecotype) stem. Data are averages of two reports $(37,46)$.

5. A. thaliana (Landsberg erecta, ecotype) leaf (46).

6. Brassica oleracea leaf (91).

7. Arachis hypogaea, branch base leaves (111).

8. Medicago sativa, seven-day old leaves (6a).

9. \% total

10. $\operatorname{tr}$, trace $(\leq 0.5 \%) .11$. N.D., not detected. 
Cuticular wax composition varies among and within species. The same plant may show organ-to-organ differences, tissue-to-tissue differences, and developmental differences. GC and scanning electron microscopy analyses have revealed organ-specific differences in wax composition and content on Arabidopsis stems (37), leaves (46), pollen (82), and siliques (53) (Figure 1); between barley spikes and leaf blades (100); and between Zea mays (maize) leaf and pollen (12). Tissue-specific differences are exemplified by the adaxial and abaxial leaf surfaces of Pisum sativa (pea) that differ by 10-fold in the level of alkanes (99). Developmental changes in wax production are observed in the leaves of Tilia tomtentosa (silver lime trees). Approximately 15

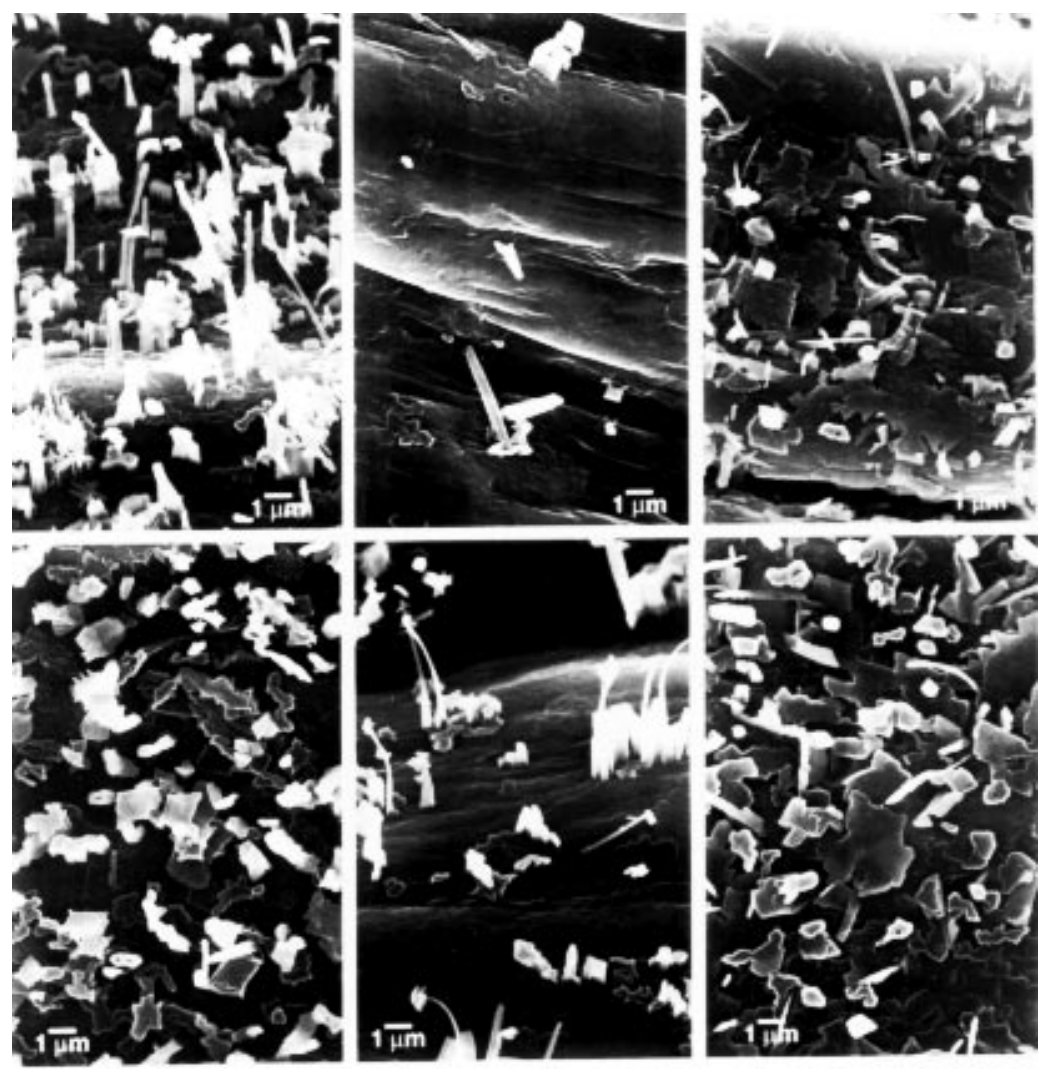

Figure 1 Scanning electron micrographs of wild-type and mutant Arabidopsis stems (top) and siliques (bottom). Wild-type stems and siliques (left) are characterized by a predominance of varied tubes and lobed plates, respectively. Stems and siliques of cer7 mutants (center) have both reduced numbers of crystals and altered crystalline structures. Siliques of cer 17 mutants differ little from wild-type siliques, whereas cer 17 stems have few tube structures characteristic of wild type (right) (J Chen \& D Post-Beittenmiller, unpublished information). 
days after unfolding, the leaves begin to synthesize large amounts of waxes, in particular $\beta$-amyrenyl acetate and long chain aldehydes (35). Another example of developmental changes in wax production is found in juvenile and adult maize leaves. Young leaves have predominantly primary alcohols (63\%), and older leaves have predominantly wax esters $(42 \%)(4,11)$. Finally, wax esters are not restricted to the cuticle but also occur as the major storage lipids in jojoba (80) and are minor components of olive oil (13).

The ubiquitous presence of cuticular wax is testimony to its essential function to waterproof the plant, and its immense diversity is evidence of its many successful adaptations to an aerial environment while enhancing its usefulness as protection for plants against biotic and abiotic stresses. Underlying this diversity are sophisticated controls on gene expression at the organ and tissue levels and under a wide range of developmental cues.

\section{De Novo Synthesis and Very Long Chain Fatty Acid Elongation}

The precursors of wax biosynthesis are fatty acids that are likely derived from de novo synthesis in plastids. In plants, de novo fatty acid biosynthesis is catalyzed by a series of enzymatic steps, collectively referred to as fatty acid synthase (FAS) (78). The initiation of fatty acid synthesis is the condensation of malonyl-acyl carrier protein (ACP) with acetyl-CoA (42), followed by the sequential reduction of 3-ketoacyl-ACP, the dehydration of 3hydroxyacyl-ACP, and the reduction of trans- $\Delta^{2}$-enoyl-ACP. The fatty acyl primer remains esterified to the ACP cofactor and is further extended-two carbons at a time-by the donor, malonyl-ACP. For each two-carbon addition, there is a sequential round of condensation, reduction, dehydration, and second-reduction steps. NAD $(\mathrm{P}) \mathrm{H}$ serve as reducing equivalents for the two reductases. The long chain products $(\mathrm{C} 16, \mathrm{C} 18)$ are subsequently processed by one or more enzymes, including stearoyl-ACP desaturase, plastidial acyltransferases, and acyl-ACP thioesterases (hydrolases). Fatty acids are then utilized for glycerolipids, waxes, or cutin and suberin biosynthesis, depending on the tissue type and developmental stage.

Although de novo fatty acid synthesis occurs ubiquitously, cuticular wax biosynthesis occurs almost exclusively in epidermal tissues $(48,59)$. The primary enzyme activity characterizing wax biosynthesis is fatty acid elongation. Among membrane lipids, only relatively minor amounts of fatty acids longer than $\mathrm{C} 18$ are found (16). In contrast, the majority of wax components are derived from very long chain fatty acids (VLCFA) that are 20-32 carbons in length; fatty acids esterified to alcohols may be 40-60 carbons in length. These VLCFAs are produced from fatty acid precursors (C16 or C18) that are elongated extraplastidially by microsomal enzymes, in a manner biochemically analogous to de novo fatty acid synthesis. The acyl chains undergo the 
same four basic reactions of condensation, reduction, dehydration, and a second reduction, for each two-carbon elongation, and these four activities are collectively termed elongases (98). Similar to FAS, NAD(P)H serve as the reducing equivalents for the elongase reducing activities (51). However, there are some notable differences between FASs and elongases. First, VLCFA elongation does not occur on ACP, and malonyl-CoA, rather than malonyl-ACP, serves as the two-carbon donor $(2,3)$. Second, elongases are extra- plastidial and membrane-associated rather than stromal and soluble $(17,107)$. Third, elongases have an apparent but as yet undefined requirement for ATP $(17,28)$. Therefore, on the basis of these differences, de novo synthesis refers to the FAS-catalyzed plastidial extension of acyl-ACPs, and elongation refers here to the microsomal extensions of the fatty acyl chain by elongases. This distinction is made for clarity because of inconsistencies in the literature in which the plastidial C16:0 to C18:0 extension is referred to as an "elongation reaction."

Because of their essential role in wax production, elongases have been one of the most studied of the wax biosynthetic steps (100). In addition, the corresponding seed elongases have also been studied extensively because the seed oil storage components of the Brassicaceae and jojoba (triacylglycerols and liquid wax, respectively) contain significant levels of the agronomically important VLCFA, erucic acid (C22:1). Seed elongase components have been cloned only recently $(41,54 a)$.

\section{Multiple Elongation Systems}

Over the past three decades, ample evidence has been obtained demonstrating multiple elongation systems involved in wax biosynthesis, which are both sequential (generating a homologous series) and parallel reactions (generating different lipid classes) (98). A single elongase catalyzing sequential reactions is exemplified by seed elongases. The condensing enzyme component of a seed elongase has been cloned from jojoba and catalyzes three elongation steps from $\mathrm{C} 18: 1$ to $\mathrm{C} 24: 1$ (54a). The corresponding gene, FAE1, has been cloned from Arabidopsis (41). Although the cloned sequences have not been expressed nor the enzyme activity assayed, the fael mutant is defective in the two elongation steps from C18:1 to $\mathrm{C} 22: 1(54,55)$. In contrast, parallel elongases catalyze extensions leading to the production of different wax classes, as shown in Figure 2. In this simplified scheme, the decarbonylation (A), acyl-reduction (B), and $\beta$-ketoacyl-elongation (C) are shown as distinct and parallel pathways. All three pathways are found in the epidermal tissue of most plants, but their relative contributions to the cuticular wax composition vary from organ to organ and species to species.

The decarbonylation pathway results in the production of aldehydes, odd chain alkanes, secondary alcohols, and ketones. Early studies referred to this 


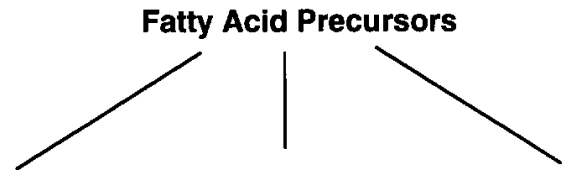

(A)

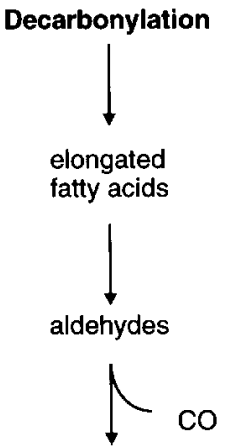

odd chain alkanes

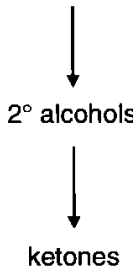

(B)
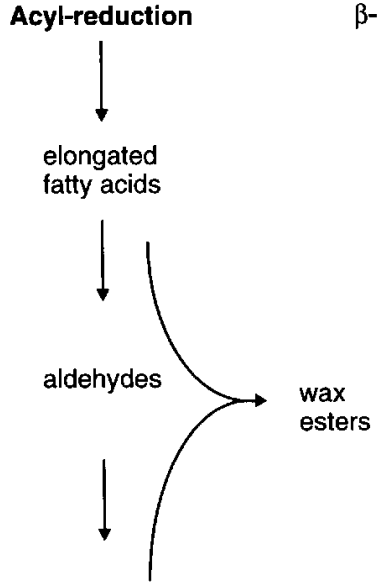

$1^{\circ}$ alcohols
(C)

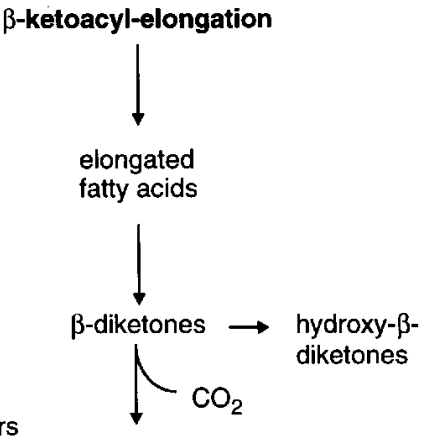

[methyl-ketones]

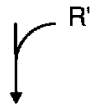

alkan-2-ol

acyl esters

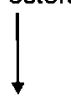

oxoalkan-2-ol

acyl esters

Figure 2 Three primary wax biosynthetic pathways. Pathways depict only the major steps and are not intended to provide biochemical detail. Although pathways are shown as distinct and separate, some intermediates (e.g. aldehydes) may be shared among the pathways.

pathway as the decarboxylation pathway because it was thought that odd chain (n-1) compounds were generated by a decarboxylation of the corresponding even chain (n) fatty acid. It was demonstrated, however, that an aldehyde intermediate is generated and that carbon monoxide, not carbon dioxide, is released (21). Although decarbonylation occurs in plants and microorganisms (23), insects use a cytochrome P450-dependent decarboxylation to generate the odd chain hydrocarbon (Z) 9-tricosene (85).

The acyl-reduction pathway produces aldehydes, primary alcohols, and wax esters derived from the esterification of fatty acids and primary alcohols. In developing jojoba seed, the two-step reduction from fatty acid to primary alcohol is catalyzed by one enzyme, and the aldehyde intermediate does not 
accumulate (80). In Brassica oleracea leaf, the aldehyde intermediate accumulates, and the two reduction steps are catalyzed by separate enzymes (49).

The $\beta$-ketoacyl-elongation pathway results in the production of $\beta$-diketones and their derivatives. $\beta$-diketones are a major component of the cuticular wax of barley spike, uppermost leaf sheath, and internode (103) and are found as minor components of other plant species such as Brassicaceae and carnation (105). Elegant analyses of barley cer-cqu mutants elucidated this third pathway and clearly demonstrated that $\beta$-ketoacyl elongation was catalyzed by an enzyme system separate from the acyl-reduction and decarbonylation systems $(69,70,102,103)$.

In some plants, the decarbonylation and acyl-reduction pathways may share some or all of the fatty acid elongation reactions and may differ only in the modifying enzymes that act on the elongated fatty acids and their derivatives. The $\beta$-ketoacyl-elongation pathway is clearly a separate and parallel elongation pathway in barley (102). Much of the data that distinguish sequential and parallel pathways are derived from inhibitor studies and the characterization of wax-deficient mutants. Studies include photoperiod and chemical inhibition (97). These studies demonstrate that an individual elongation step or a single pathway may be affected without affecting the other parallel pathways. For example, dithiothreitol and 3-mecaptoethanol inhibit synthesis of hydrocarbons but do not affect $\beta$-diketone synthesis. In contrast, cyanide affects $\beta$-diketone synthesis but not hydrocarbon synthesis (70). Similarly, the sequential condensation steps of de novo fatty acid biosynthesis are differentially inhibited by some of the same chemicals. Cerulenin, a wellcharacterized inhibitor of 3-ketoacyl synthases, specifically inhibits the C20 to C22 elongation step in leek epidermis (2) but has no effect on the sequential elongation of C22 (28). In contrast, cerulenin does not inhibit the seed elongases of Brassica napus or Arabidopsis (A Hlousek Radojcic, H Imai \& J Jaworski, personal communication). Individual mutants in Arabidopsis and maize specifically block $\mathrm{C} 28$ and $\mathrm{C} 30$ elongation steps $(6,37)$. These studies together suggest that there may be many elongase systems involving seven sequential reactions for two or three parallel pathways. In the case of the condensing enzymes for de novo fatty acid synthesis, the chain-length specificities are not rigid and show some overlapping activities in vitro. This may also be true for the elongase condensing enzyme reactions. Evidence indicates that the modifying reactions (e.g. aldehyde reductase) do not have chain length specificities (52). However, these conclusions are based on measurements of in vitro activities and should be viewed with caution. In vivo activities may be more selective than in vitro activities.

The parallel pathways are responsible for the wide diversity of cuticular wax composition. Each parallel pathway consists of sequential elongation reactions that terminate with chain modifications or with the release of free 
elongated fatty acids. However, the extent to which the intermediates are shared among pathways is unclear. For example, aldehydes are intermediates of both the decarbonylation and the acyl-reduction pathways, but it is not known whether one fatty acid reductase generates aldehydes for both the decarbonylase and the aldehyde reductase (such that these enzymes compete for the same substrate pool) or whether there are two fatty acid reductases and channeling of substrates limits competition. Arabidopsis cer4 mutants are postulated to be defective in aldehyde reductase $(37,46)$. In the mutant plants, there is a large increase in aldehydes and a decrease in primary alcohols (acyl-reduction pathway) but no change in the products (alkanes, secondary alcohols, and ketones) of the decarbonylation pathway $(37,46)$. The C28 primary alcohol predominates in wild-type CER4, whereas the $\mathrm{C} 30$ alcohol predominates in the mutant cer4 (37). This surprising result suggests that the $\mathrm{C} 28$ fatty acid, in the absence of a $\mathrm{C} 28$ reductase activity, is elongated to the $\mathrm{C} 30$ fatty acid and reduced to the corresponding alcohol (presumably through an aldehyde intermediate) but apparently does not enter the decarbonylation pathway, because there is no increase in the C29 alkane (46a). The lack of an increase in alkanes indicates that aldehyde intermediates may not be readily shared between the pathways, such as might occur when parallel pathways exist as organized complexes.

\section{BRANCH POINTS WITH OTHER LIPID BIOSYNTHETIC PATHWAYS}

Fatty acids produced in the plastid from de novo synthesis are utilized by at least three biosynthetic pathways that lead to the production of glycerolipids, waxes, and cutin or suberin. The partitioning of fatty acyl precursors among these pathways is likely to be a key regulatory point that controls both the quantity and quality of cuticular lipids. In most vegetative tissues, de novo synthesized $\mathrm{C} 16: 0$ and $\mathrm{C} 18: 1$ are the fatty acid precursors for glycerolipid biosynthesis, whereas the precursors for cuticular wax biosynthesis are primarily saturated fatty acids, probably derived from C18:0 as discussed below, although alkenes are minor components of some cuticular waxes (105). Cutin and suberin are polymers of C16:0 and C18:1 hydroxy fatty acids (14, 50). Thus, following de novo fatty acid biosynthesis, a partitioning occurs that delivers $\mathrm{C} 16: 0$ and $\mathrm{C} 18: 1$ fatty acids to glycerolipid or cutin/suberin biosyntheses and C18:0 to wax biosynthesis. Presently, the mechanisms that regulate this partitioning are not understood. Partitioning of precursors into these pathways may be accomplished by enzyme specificities or by substrate availabilities (compartmentalization and/or metabolic channeling). For example, storage and membrane glycerolipids exhibit strong fatty acid bias because of the substrate specificities of acyl transferases (31). Such specificity, however, may only be necessary for branch point enzymes, and enzymes 
later in the branch pathway may not exhibit narrow substrate specificities. An alternative is that fatty acid partitioning may arise from the supply of specific fatty acids in individual cell types. For example, saturated fatty acids may be elongated in epidermal cells because they are the most abundant in those cells. Similarly, monounsaturated fatty acids may be elongated in seeds because they are most abundant in seeds. Partitioning may therefore be due to the supply of fatty acids rather than to the specificities of the enzymes utilizing the fatty acids.

\section{Termination of Plastidial Fatty Acid Biosynthesis}

A tissue in which substantial partitioning must occur (among glycerolipid, wax, and cutin biosyntheses) is leek epidermis. In leek, epicuticular waxes comprise $>15 \%$ of the total leaf lipid (exclusive of cutin) of which $>90 \%$ is derived from saturated precursors (61; D Post-Beittenmiller, unpublished data) Only the epidermal cells, which constitute $<4 \%$ of the leaf fresh weight, contribute to the wax layer. Unlike other cell types in plant vegetative organs (where lipid synthesis utilizes about $10 \%$ of the carbon), lipid synthesis in epidermal cells is probably the most dominant metabolic pathway to which carbon is allocated. Potentially significant steps in the regulation of wax production in the epidermis are first, the generation of sufficient fatty acid pools and second, the partitioning of fatty acid precursors among wax biosynthesis, membrane glycerolipid, and cutin or suberin biosynthesis. Therefore, it is important to understand how epidermal cells generate sufficiently large pools of saturated fatty acids (probably C18:0) to support wax biosynthesis while limiting their entry into glycerolipid and cutin or suberin biosynthesis.

When total leaf extracts are assayed for acyl-ACP hydrolyzing activity (acyl-ACP thioesterases), the major activity is directed against oleoyl-ACP (18:1-ACP) (79), which reflects the abundance of unsaturated fatty acids in total leaf glycerolipids. However, when epidermal tissue is removed and assayed separately, acyl-ACP hydrolyzing activities toward saturated acylACPs are significantly higher compared with total leaf extracts (61). Both palmitoyl-ACP (16:0-ACP) and stearoyl-ACP (18:0-ACP) hydrolyzing activities are present in leek (Allium porrum) epidermis (61; D Liu \& D PostBeittenmiller, unpublished manuscript). The stearoyl-ACP thioesterase (STE) activity is highly, if not exclusively, expressed in epidermis and has a high specificity for 18:0-ACP (61). Although additional studies directly linking STE activity with wax production are required, the relative activities of stearoyl-ACP desaturase and STE are presumed to be responsible for generating the extraplastidial stearate pool in the epidermis.

Either palmitate $(\mathrm{C} 16: 0)$ or stearate $(\mathrm{C} 18: 0)$ could be the initial saturated substrate for wax biosynthesis. The relative levels of these two fatty acids are determined in part by the activity of 3-ketoacyl-ACP synthase II (KAS II), 
which catalyzes the two-carbon extension from C16:0 to C18:0 (88). It was previously reported that KAS II activity is not detectable in leek epidermis, which suggested that extraplastidial elongation begins with C16:0 (60). However, in rapidly expanding leek epidermis, KAS II activity is detected (81). Substrate specificity studies of microsomal elongases (prepared from rapidly expanding leek epidermis) also indicate that the rate of C16:0 elongation is low compared with the rate of C18:0 elongation (KJ Evenson \& D PostBeittenmiller, unpublished manuscript). Similarly, jojoba elongase utilizes C16:0 approximately 10- to 20-fold less efficiently than C18:0 (54a). The occurrence of an epidermally expressed STE also implies that there is a pool of stearoyl-ACP in leek epidermis on which this enzyme acts. These data together suggest that stearoyl-ACP is generated in the epidermis by KAS II, the stearoyl-ACP is hydrolyzed by STE, and extraplastidial elongation begins with a C18:0 primer. It should be noted that there are also palmitoyl-ACP thioesterases (24; D Liu \& D Post-Beittenmiller, unpublished manuscript) that may generate extraplastidial palmitate. This palmitate, however, may be a precursor for glycerolipid and cutin biosynthesis rather than a substrate for elongation.

An alternative mechanism for partitioning fatty acids into wax, glycerolipid, or cutin or suberin biosynthesis may be based, in part, on the substrate specificity of the elongase. Agrawal and coworkers demonstrated that leek microsomal elongases utilize only saturated endogenous primers (2). However, when longer monounsaturated primers $(\geq \mathrm{C} 20: 1)$ are supplied, these are elongated (3). The researchers postulated that the specificity for saturated primers lay with the first elongation step (C18:0 to $\mathrm{C} 20: 0)$ and that monounsaturated primers (C20:1) could be elongated as well as the corresponding saturated primers. In contrast, the partially purified leek epidermal elongase does not show a strict substrate specificity; it will elongate C18:1 as well as C18:0 (57). Recent studies with microsomes prepared from rapidly expanding leek show a preference for C18:0 > C16:0 > C18:1 (KJ Evenson \& D Post-Beittenmiller, unpublished manuscript). In addition, seed extracts from Arabidopsis (54) and jojoba (54a) will elongate saturated primers (C18:0 to C24:0) at rates comparable to the corresponding monounsaturated primers, although the seed oils contain VLC monounsaturated fatty acids. One simple explanation for these apparently contrasting results in seed is that the in vivo supply of fatty acids is predominantly monounsaturated and that elongases do not have a strict substrate specificity; rather, they elongate whatever fatty acid is supplied.

\section{What Are the Substrates for Elongase Condensing Enzymes?}

As discussed above, following termination of plastidial fatty acid synthesis and export of the fatty acid out of the plastid, fatty acids are extended by membrane-associated elongases. In both plants and animals, in vitro fatty acid elongation occurs when microsomes from appropriate tissues are incu- 
bated with labeled malonyl-CoA, $\mathrm{NAD}(\mathrm{P}) \mathrm{H}$, and ATP. This activity is independent of supplied fatty acyl primer; therefore, a pool of endogenous primer is present in microsomal preparations. In leek epidermal microsomes, this pool is substantial because elongation in the absence of primer is $80 \%$ of the activity in the presence of supplied primer (28). When supplied, both acyl-CoAs and free fatty acids are effectively elongated by microsomes, but the elongation of fatty acids has an absolute requirement for ATP. Elongation rates in the presence of acyl-CoA but in the absence of ATP are 10-20\% of the rates in the presence of ATP. The ATP requirement has often been attributed to its involvement in acyl-CoA synthetase (ligase) activity that generates and/or maintains the acyl-CoA primer pool (58). In a recent review of animal elongation systems, Cinti concluded that the ligase activity under standard elongation conditions (in the absence of supplied CoASH and fatty acids) is not adequate to provide sufficient levels of acyl-CoA primer to achieve the microsomal elongation rates routinely observed (22). Similar comparisons can be made with respect to plant fatty acid elongation. First, the maximum rates of elongation (in the absence of supplied CoASH) by plant microsomes range from 12 to $20 \mathrm{nmol} / \mathrm{mg} / \mathrm{h}(18,28)$ compared with the maximal rates $(<2 \mathrm{nmol} / \mathrm{mg} / \mathrm{h})$ of microsomal acyl-CoA synthesis when no CoASH was supplied (58). The apparent $K_{\mathrm{m}}$ for CoASH in developing safflower microsomes is $24 \mu \mathrm{M}$ (40). Under standard elongation conditions (in which CoASH is not supplied), the CoASH required for acyl-CoA synthetase activity must either be endogenous or result from the addition of malonyl-CoA. Commercial preparations of $\left[{ }^{14} \mathrm{C}\right]$ malonyl-CoA contain $<1 \%$ CoASH. Even if $10 \%$ of the added malonylCoA (typically $100 \mu \mathrm{M}$ is used) were hydrolyzed because of microsomal hydrolases or improper storage conditions, the CoASH concentration would only be $10 \mu \mathrm{M}$, well below the $K_{\mathrm{m}}$ for CoASH. In addition, if acyl-CoA synthetase is required for elongation of fatty acids, addition of CoASH should stimulate elongase activity. However, fatty acid elongation in microsomes from rapidly expanding leek is inhibited by CoASH (28). Thus, this kinetic analysis indicates that it is not possible for the microsomal acyl-CoA synthetase to generate sufficient acyl-CoA primer for the elongation reaction (40, 58; KJ Evenson \& D Post-Beittenmiller, unpublished manuscript).

For reasons cited above, it seems unlikely that ATP is required for acylCoA synthesis. If this is true, then why is ATP required, and how are free fatty acids elongated by microsomal elongases? There may be another activated form of the fatty acid that serves as the primer for elongation. For example, ATP may activate free fatty acids to an adenylated intermediate, similar to the acyl-AMP intermediate generated in the synthesis of acyl-CoA:

In the absence of an activated precursor, ATP hydrolysis may enable the free fatty acid to bind directly to an active site cysteine of the condensing enzyme, or it may provide energy for the condensation reaction. 
Further evidence that acyl-CoA may not be the immediate substrate for elongation comes from isotope dilution studies using microsomes from developing Brassica napus seeds (39a). In these studies, [14C]18:1-CoA was used as the supplied primer and the percent ${ }^{14} \mathrm{C}$ of the substrates and the elongated products were analyzed by GC/MS. These studies revealed that the endogenous pool of C18:1-CoA was quite small and that the pools of C20:1$\mathrm{CoA}$ and $\mathrm{C} 22: 1-\mathrm{CoA}$ were undetectable in freshly prepared microsomes, whereas newly synthesized pools of C20:1- and C22:1-CoAs were readily detected after 10 min of incubation with ATP and malonyl-CoA. The percent ${ }^{14} \mathrm{C}$ in the elongated $\mathrm{C} 20: 1-\mathrm{CoA}$ product was found to be 2-3-fold less than the percent ${ }^{14} \mathrm{C}$ of the starting C18:1-CoA substrate, which indicates that the $\left[{ }^{14} \mathrm{C}\right] 18: 1$ moiety from the $\left[{ }^{14} \mathrm{C}\right] 18: 1-\mathrm{CoA}$ was diluted by an endogenous pool other than C18:1-CoA. Preliminary results with microsomes prepared from leek epidermis were similar (A Hlousek-Radojcic, KJ Evenson, D PostBeittenmiller \& JG Jaworski, unpublished manuscript). Clearly, in plants as well as animals, the ATP requirement and the nature of the primer are not adequately understood.

\section{Partitioning Between Wax and Cutin or Suberin}

Cutin is a major component of a plant's aerial surfaces, whereas suberin is a polymer associated with roots and wound sites. Cutin or suberin form the insoluble polymeric matrices that are impregnated with wax. They are biochemically and biosynthetically related to wax because they are biopolymers of oxygenated fatty acids $(14,50,51)$. They are functionally related to wax in that they are part of the cuticle and therefore serve as the initial barrier to the environment. Cutin and suberin monomers are derived from C16:0 and C18:1 fatty acids synthesized in the plastid (51). They are generated by a family of mixed-function oxidases with activities similar to those of the decarbonylation and $\beta$-diketoacyl-elongation pathways for wax biosynthesis $(14,100)$, although the cutin/suberin oxidases probably do not utilize VLC precursors.

Cutin is made exclusively in the epidermis and therefore is another branch point for partitioning fatty acid precursors. The contribution of saturated fatty acids (as palmitate) is significant for C16:0-derived monomer biosynthesis; therefore, partitioning between wax and cutin biosynthesis cannot be based solely on saturation or unsaturation but must also be based on chain length. Similarly, the monounsaturated fatty acid (C18:1) must be partitioned between glycerolipids and cutin. Glycerolipids do contain some saturated C16:0 (16\%) and C18:0 (1\%) fatty acids (15a), and limiting rather than excluding saturated fatty acids is an important part of partitioning. In Figure 3, a simple schematic illustrating the complexity of partitioning C16 and C18 fatty acids among the three major lipid synthetic pathways in epidermis in shown. 


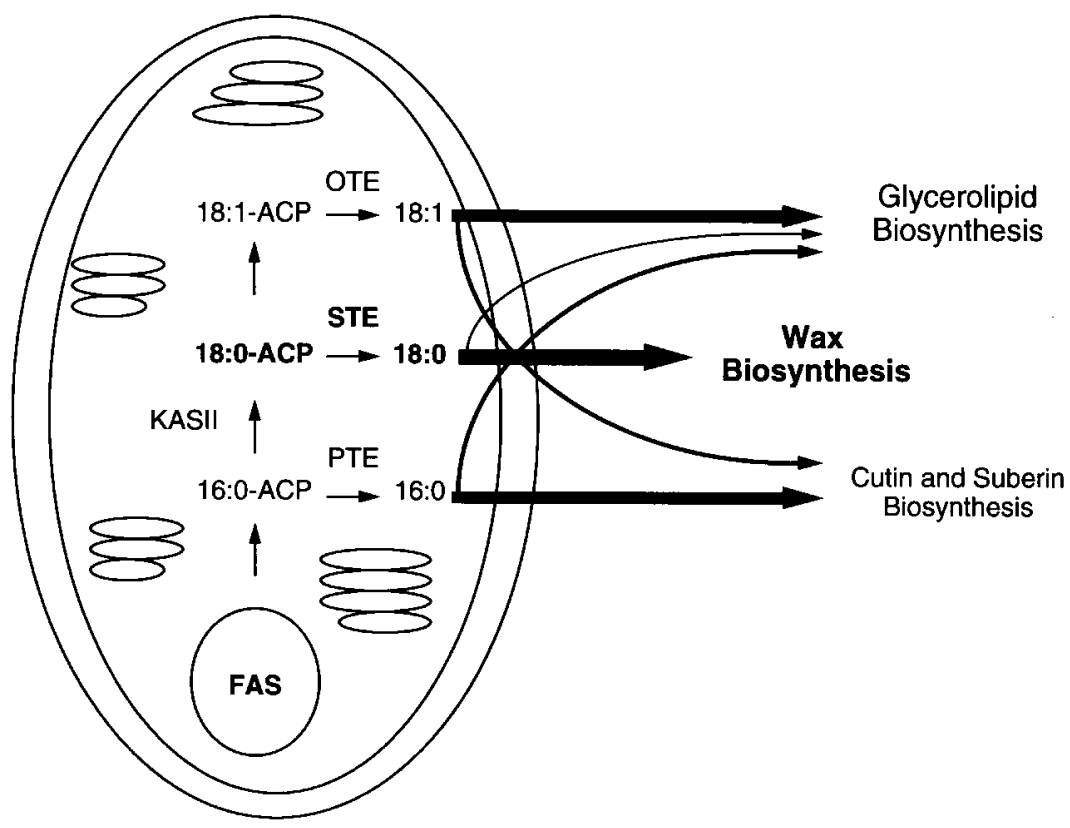

Figure 3 Schematic showing export of fatty acids from the plastid and partitioning between the three lipid biosynthetic pathways in epidermis. FAS, fatty acid synthase; KAS II, 3-ketoacyl-ACP synthase II; OTE, oleoyl-ACP thioesterase; PTE, palmitoyl-ACP thioesterase; STE, stearoyl-ACP thioesterase.

\section{MOVEMENT TO THE OUTER SURFACES}

One of the still mysterious aspects of cuticular wax production is the movement of hydrophobic wax components to the plant surface. Early SEM studies led to speculation about two modes of movement: passage through welldefined pores and general diffusion through microscopic spaces in the cell wall (43). The former hypothesis is based on the uneven distribution of wax epicuticular structures and the presence of putative pores on the surfaces of some plants (100). The latter hypothesis is based on the ubiquitous and amorphous coating of wax throughout the cuticle and over the plant surface, and it suggests that cuticular wax is exported at continuous or very frequent intervals. The epicuticular crystalline structures most likely result from the physical-chemical properties of the wax, i.e. the concentrations and types of the specific components, rather than as a result of a transport process. Correlations between wax composition and wax structure, as discussed above, support this hypothesis. Recrystallization studies of wax on spruce needles (that were mechanically injured) show that wax tubes re-form to their original crystalline structure even on nonviable needles, i.e. in the absence of new 
synthesis or export (7). SEM studies of Sorghum sheath tissues demonstrate that wax filaments are secreted at sites around papillae (raised surfaces) on the cork cells. These filaments are associated with intracellular vesicles whose density increases as wax production is induced by light (45). There is no evidence for channel or pore involvement. Although the composition of the vesicles is unknown, they may contain proteins involved specifically in the transport of wax components to the cell surface.

Lipid transfer proteins (LTP) are small, abundant basic proteins that were first identified in animals as possible intracellular carriers of lipids (between membranes or between organelles). They have also been found in microorganisms and in plants (110). The lipid transfer function of plant LTPs has been reported for spinach leaves (86), maize seedlings (25), barley seeds (15, 66), and castor beans (106). They are expressed in the epidermal tissues of a variety of organs including barley aleurone cells (47), leaves and coleoptiles (32), apical meristems (30), and flower buds, but not in roots (83). Immunogold localization studies indicate LTPs are cell wall proteins (94). They have also been isolated from the surface waxes of plants (84). The discovery that LTPs move vectorally into the lumen of the endoplasmic reticulum (8, 67) and are secreted to the cell walls and outer surfaces led to speculation that they may be involved in transporting cuticular lipid components (waxes and cutin or suberin monomers) $(89,90)$. Although it has been postulated that LTPs transport lipids through the ER and deposit them on the outer surfaces, the abundance of lipid molecules compared with LTPs is a strong stoichiometric argument against such intracellular transfer. Furthermore, the LTPs do not return to the ER lumen for additional lipid transfer, which limits the number of lipid molecules that could be transferred. It is more likely that the movement of LTPs into and through the ER lumen is part of their own secretion process and that association with lipids in the lumen is due to the hydrophobic nature of LTPs. After LTPs are secreted to the outside of the cell wall and cuticle, an environment in which LTPs are likely to move freely, they may be part of a facilitated diffusion mechanism that moves cuticular lipids from the outer layer of the plasma membrane, through the cell wall and cuticle, to the plant surface.

\section{GLOSSY MUTANTS AND THE CLONING OF WAX- RELATED GENES}

Mutants with deficient or altered wax coatings have been identified by their nonglaucous or glossy appearance. There are no reports of mutants that are completely deficient in cuticular wax, probably because of the vital function that waxes play in waterproofing the plant cuticle. In many plants, the mutant phenotypes affecting the major wax classes are easily observed by visual ex- 
Table 2 Mutants defective or altered in wax production ${ }^{\mathrm{a}}$

\begin{tabular}{|c|c|c|c|c|}
\hline Species & Locus & Biochemical and genetic phenotype ${ }^{b}$ & Cloned & References \\
\hline \multirow[t]{3}{*}{ Barley } & cer-cqu ${ }^{\mathrm{c}}$ & $\begin{array}{l}\text { a. loss of } \beta \text {-ketoacyl elongation pathway } \\
\text { b. defective in } 3 \text { enzymatic functions } \\
\text { c. multifunctional protein }\end{array}$ & no & 102,103 \\
\hline & $\operatorname{cer}^{-y y^{\mathrm{c}}}$ & $\begin{array}{l}\text { a. dominant (all } 17 \text { alleles) } \\
\text { b. regulatory } \\
\text { c. affects two pathways } \\
\text { d. changes spike wax into leaf wax }\end{array}$ & no & 62 \\
\hline & cer- $n^{\mathrm{c}}$ & $\begin{array}{l}\text { a. both dominant and recessive alleles } \\
\text { b. affects two pathways } \\
\text { c. regulatory }\end{array}$ & no & 63 \\
\hline \multirow[t]{11}{*}{ Maize } & $g l 1^{\mathrm{c}}$ & $\begin{array}{l}\text { a. blocks early steps or interferes with } \\
\text { precursor supply } \\
\text { b. epistatic relationships: } g l 8>g l l>g l 7\end{array}$ & $\begin{array}{l}\text { transposon } \\
\text { tagged, gene } \\
\text { product } \\
\text { unknown }\end{array}$ & $\begin{array}{l}6,39,65 \\
96\end{array}$ \\
\hline & $\begin{array}{l}g l 2, g l 4 \\
\quad g l 16\end{array}$ & $\begin{array}{l}\text { a. structural genes } \\
\text { b. blocks C30 elongation }\end{array}$ & $g l 2$ and $g l 4$ tagged & 6,96 \\
\hline & $g l 3$ & $\begin{array}{l}\text { a. structural gene } \\
\text { b. blocks C28 elongation }\end{array}$ & transposon tagged & 6,65 \\
\hline & $\mathrm{gl5}$ & $\begin{array}{l}\text { a. increased aldehydes, block in } \\
\text { aldehyde reductase }\end{array}$ & transposon tagged & 65 \\
\hline & $g l 6$ & & transposon tagged & 65 \\
\hline & gl7 & $\begin{array}{l}\text { a. regulatory gene } \\
\text { b. blocks early steps } \\
\text { c. epistatic relationships: } g l 8>g l l>g l 7\end{array}$ & no & 6 \\
\hline & $g l 8^{\mathrm{c}}$ & $\begin{array}{l}\text { a. blocks early steps or interferes with } \\
\text { precursor supply } \\
\text { b. epistatic relationships: } g l 8>g l l>g l 7\end{array}$ & $\begin{array}{l}\beta \text {-ketoacyl } \\
\text { reductase }^{\mathrm{d}}\end{array}$ & $\begin{array}{l}6,39,65 \\
96\end{array}$ \\
\hline & $g l 9^{\mathrm{c}}$ & a. altered leaf morphology & no & 87 \\
\hline & $g l 11$ & $\begin{array}{l}\text { a. structural gene for EDIa component } \\
\text { b. loss of aldehydes with no loss of } 1^{\circ} \\
\text { alcohols } \\
\text { c. possible fatty acid reductase }\end{array}$ & no & 6 \\
\hline & gl12 & & transposon tagged & 6,65 \\
\hline & $g l 15^{\mathrm{c}}$ & $\begin{array}{l}\text { a. mutant precociously develops adult } \\
\text { leaves } \\
\text { b. glossy phenotype is secondary }\end{array}$ & $\begin{array}{l}\text { homologue of } \\
\text { APETALA2 }^{\mathrm{d}}\end{array}$ & $27,73,96$ \\
\hline Sorghum & bm22 & a. cuticle mutant with reduced wax load & no & 44 \\
\hline \multirow[t]{4}{*}{ Arabidopsis } & $\operatorname{cer} 1^{\mathrm{c}, \mathrm{d}}$ & a. structural gene for decarbonylase & $\begin{array}{l}\text { transposon and } \\
\text { T-DNA tagged }\end{array}$ & $\begin{array}{l}1,37,46 \\
53,56\end{array}$ \\
\hline & $\operatorname{cer} 2^{\mathrm{c}}$ & $\begin{array}{l}\text { a. regulatory } \\
\text { b. blocks C } 28 \text { elongation and accum- } \\
\text { ulates products of reductive pathway } \\
\text { c. altered stem wax but normal leaf wax }\end{array}$ & $\begin{array}{l}\text { T-DNA tagged } \\
\text { and cloned by } \\
\text { walking, gene } \\
\text { product } \\
\text { unknown }\end{array}$ & $\begin{array}{l}37,39,46 \\
53,75\end{array}$ \\
\hline & cer3 & $\begin{array}{l}\text { a. release of fatty acid from elongase } \\
\text { complex }\end{array}$ & T-DNA tagged & $\begin{array}{l}37,38,46, \\
53\end{array}$ \\
\hline & cer4 & a. block in aldehyde reductase & T-DNA tagged & $\begin{array}{l}36,37,46, \\
53,56\end{array}$ \\
\hline
\end{tabular}


Table 2 (continued) ${ }^{\mathrm{a}}$

\begin{tabular}{|c|c|c|c|c|}
\hline Species & Locus & Biochemical and genetic phenotype $^{b}$ & Cloned & References \\
\hline & $\operatorname{cer} 6^{\mathrm{c}}$ & $\begin{array}{l}\text { a. blocks C28 elongation } \\
\text { b. male sterile }\end{array}$ & T-DNA tagged & $\begin{array}{l}46,53,56, \\
82\end{array}$ \\
\hline & $\operatorname{cer} 7$ & a. altered stem wax but normal leaf wax & walking & $29,46,53$ \\
\hline & $\begin{array}{l}\text { cer } 8, \text { cer } 9 \\
\quad \text { cer } 19\end{array}$ & a. block in substrate transfer & & 46,53 \\
\hline & cer10 & & T-DNA tagged & 53,56 \\
\hline & cer 21 & & T-DNA tagged & 56 \\
\hline
\end{tabular}

${ }^{\mathrm{a}}$ Not intended to be a comprehensive list of wax defective mutants but rather illustrative. Putative gene product based on phenotype only.

${ }^{\mathrm{b}}$ All mutants exhibit a glossy (nonglaucous) phenotype unless indicated otherwise.

${ }^{\mathrm{c}}$ See text for more information.

${ }^{\mathrm{d}}$ Gene identity based only on sequence similarities, not on functional assays.

amination. Therefore, this phenotype is used extensively as a marker for genetic studies and in breeding programs. Changes in a minor wax component are less likely to have a discernible effect and therefore have not been found. Similarly, plants that overproduce wax are not readily detected by a visual screen. Table 2 is a partial listing of wax mutants in barley, maize, Sorghum, and Arabidopsis, their phenotypes, and reported progress toward the isolation of corresponding genes. Wax-deficient mutants have also been found in other species, such as pea and broccoli, but are not listed here.

\section{Barley}

Some of the most elegant characterizations of glossy or eceriferum (cer) mutants have been conducted in barley by von Wettstein-Knowles and coworkers $(97,98,100)$. More than $1560 \mathrm{cer}$ mutants have been characterized representing 85 complementation groups (100). Most of these complementation groups probably represent loci that are involved in the production of cuticular wax (biosynthesis, transport, and regulation), although developmental genes (as discussed below for maize gl15) cannot be ruled out at this time. More than 30 enzymatic steps are required for the biosynthesis of the major wax components in most plants. This estimate is undoubtedly low because it does not account for differences in organ-specific or developmental expression, differences in substrate chain length specificities, transport to the plant surface, or biosynthesis of minor components. Differences in substrate specificities would presumably result from isozymes (i.e. different loci), whereas differences in expression may be due to a single gene that is differentially expressed under a variety of developmental stages; or differences in expression may be due to several genes, each expressed only during specific developmental stages or in specific organs. These levels of regulatory complexity would further increase the number of loci that could potentially result in mu- 
tant phenotypes. Furthermore, the majority of mutant phenotypes do not suggest specific blocks in the pathways, possibly because the pathways share intermediates or because they represent mutations in regulatory genes.

Genetic studies have contributed greatly to our understanding of wax biosynthesis and, in particular, to the biosynthesis of $\beta$-diketones and their derivatives. The most illustrative studies are of the cer-c, $-q$, and $-u$ mutants. These three complementation groups are tightly linked, and double and even triple mutants were isolated relatively frequently (13 times out of $1252 \mathrm{cer}$ mutants), whereas multiple mutants of other cer loci were never seen (102). Reversion studies of the double mutants show that single mutational events revert both phenotypes simultaneously. This indicates that the three loci are part of a multifunctional gene, $c e r-c q u$, and that each complementation group represents a separate functional domain (103). Mutants defective in one or more of these loci are blocked in the $\beta$-ketoacyl-elongation pathway, but the acyl-reduction and decarbonylation pathways are relatively unaffected. Defects in cer- $q$ block the synthesis of all $\beta$-ketoacyl-derived lipids; therefore, cer- $q$ acts early in the pathway or affects the first branch point. The cer-c mutant accumulates alkan-2-ols, which indicates a block in $\beta$-diketone-derived lipids. The cer- $u$ mutant has a decreased level of hydroxy- $\beta$-diketones and accumulates $\beta$-diketones, which suggests a block in a hydroxylase.

Some mutants (cer-yy and cer- $n$ ) are candidates for regulatory genes. All 17 cer-yy alleles are dominant and change the primary alcohol composition of barley spike wax into a composition indistinguishable from that of wildtype barley leaf blade wax (62). To account for this phenotype, the authors hypothesized that the mutant cer-yy allele activates the acyl-reduction pathway in leaf blades and suppresses the acyl-reduction and $\beta$-ketoacylreduction pathways in barley spikes. The dominant nature of this mutant and the fact that it affects three pathways are supportive evidence that it is regulatory. The cer- $n$ gene is also potentially regulatory (63). This locus affects all lipid classes and has both dominant and recessive alleles, a property more frequently found among regulatory genes.

\section{Maize and Sorghum}

Because maize and Sorghum seedlings have a glaucous appearance and adult leaves are glossy, visual screens for wax mutants are done at the seedling stage. This method of screening led to the isolation of some glossy mutants not involved in wax biosynthesis. Rather, they are pleiotropic; the wax defect is secondary. Probably the best example of this is the gll5 mutant in maize. This mutant was originally characterized as defective in the elongation-decarboxylation II pathway (ED-II) resulting in the production of wax esters that are characteristic of adult leaves (10). Subsequent characterization and cloning of Gl15 demonstrated that this gene is involved in epidermal differentiation 
and that the mutant defect is a premature transition from juvenile (glaucous leaves) to adult (glossy leaves) $(27,73)$. Sequencing of the $G l 15$ gene revealed that it is a homologue of APETALA2, a homeotic flower gene in Arabidopsis (73). Similar to $g l 15$, the glossy phenotype of $g l 9$ may be secondary to a developmental lesion because it has an abnormal leaf morphology (87).

Many of the maize glossy genes have been tagged (Table 2) using a variety of transposons. One of the most striking observations to come from the characterization of tagged alleles is that wax production is clearly cell autonomous. In many cases where a transposon has excised, individual cells and sectors are covered with wax crystals, whereas adjacent cells are devoid of wax structures $(20,64,87)$.

Maddaloni and coworkers reported that $g l l$ either blocks an early step in the ED-I pathway or interferes with the supply of precursors to ED-I (64). This mutant has a dramatic reduction of alkanes, aldehydes, and alcohols, but the level of esters is similar to wild type (note that the percentage of esters is higher, whereas the actual level is comparable). The recently cloned gene, $G l 8$, has sequence similarity to $\beta$-ketoacyl reductases, which suggests $G l 8$ may encode part of an analogue $(39,109)$. The $g l 8$ mutant is epistatic to $g l l$ because the aldehyde content of the $g l 1, g l 8$ double mutant is more similar to $g l 8$ than to $g l l$ (5). However, the $g l l, g l 8$ double mutant has an increased level of shorter chain aldehydes, greater than that of either parent, and suggests a synergistic effect (to this reviewer). Consequently, the relationship between $g l l$ and $g l 8$ is unclear.

\section{Arabidopsis}

In the past decade, Arabidopsis has become the model plant system for genetics and molecular biology. Therefore, it is not surprising that it should also become a model system for genetics and molecular biology of epicuticular wax production. More than 21 complementation groups resulting in a glossy phenotype have been identified in Arabidopsis. In many cases, multiple alleles have been isolated, but for some, only one allele has been found $(37,46$, 53). Because of the limited number of alleles and for reasons cited above, it is unlikely that the wax biosynthetic pathway has been saturated with mutations in Arabidopsis. Compositional analyses of wild-type and cer mutants have been conducted on stems $(37,46)$ and leaves $(46)$, and possible gene products or blocked steps have been proposed (Table 2). There are also significant differences between Arabidopsis ecotypes (46).

Hannoufa and coworkers postulated that cer2 blocks $\mathrm{C} 28$ elongation because of the almost complete loss of the $\mathrm{C} 29$ alkane, the single major component of stem waxes, and an increase in the shorter chain homologues. Jenks and coworkers see a similar decrease in the C29 alkane, but they postulate that cer 2 may have regulatory functions, based on differences in the wax 
composition between leaf and stem. Such organ differences, however, may only indicate that $C E R 2$ is differentially expressed because the leaf wax of cer 2 is virtually identical with that of wild-type leaf. CER2 has been cloned and encodes a $47-\mathrm{kDa}$ novel protein. The transcript level is high, as might be expected for a structural gene (75). If CER2 encodes a component of the elongase complex, it is surprising that it shows no apparent homology to any of the fatty acid synthase proteins. It will be very interesting to see how this story unfolds with the further characterization of the cloned CER2.

Several of the cer mutants also show reduced fertility (53). Recently, a new mutant allele of CER6 was isolated by a screen for male sterile plants (82). The pollen of the cer6 mutant is viable as assessed by in vitro germination, but it is desiccation-intolerant under normal growing conditions because of reduced wax levels on pollen surfaces. Similar to other cer6 isolates, fertility is rescued by increasing humidity around the flowers. Interactions between the mutant pollen and the wild-type stigma are aberrant, however, because callose was formed and pollen germination was apparently random. Because of these incompatibility responses, the authors suggest that pollen wax plays a role in pollen-stigma interaction.

\section{Tagging and Walking}

Tremendous advances in map-based cloning techniques make it possible to clone many genes that were previously known only by phenotype. In virtually none of the wax mutants characterized in any plant species has a gene function been unequivocally identified on the basis of the mutant phenotype. No loss of a specific enzyme activity has been correlated with any cer or glossy mutant. To date, the identity of only one wax gene ( $g l 8$ in maize, cloned by transposon tagging) has been revealed by sequence similarity to $3-$ ketoacyl reductase, but its role in wax biosynthesis has yet to be demonstrated. The CERl gene from Arabidopsis has also been cloned by transposon tagging (1). The protein encoded by CERl has His residues that are thought to be metal-binding sites. The decarbonylase that leads to the production of odd chain alkanes in the alga, Botryococcus braunii, is a cobalt-requiring enzyme (23). This information, combined with wax compositional data showing a reduction in alkanes and an increase in aldehydes (37), indicates that CER1 encodes a decarbonylase (1). Three additional Arabidopsis genes (CER2, 3, and 4) have been reportedly cloned $(36,38,75)$, but their gene products have not been identified at the time of this review. There are at least seven tagged CER loci in Arabidopsis, one of which, CER2, has also been isolated by chromosome walking (Table 2). T-DNA tagging has been used for most, but there are increasing reports of CER loci tagged by transposons $(1,39,64,65,96)$. Clearly, the tagging and cloning of genes will open up new areas of research. 


\section{Expressed Sequence Tags}

With the availability of more than 20,000 expressed sequence tags (EST) from Arabidopsis (76), it is now easier to identify clones on the basis of their sequence similarities to known genes. The identification of wax biosynthetic genes is no exception. Given that most of the enzymes are membrane associated, this approach has advantages over protein purification strategies. Because of the sequence similarities between the cloned jojoba condensing enzyme and previously cloned KAS IIIs, the identity of the jojoba clone was determined (39a). Similarly, the jojoba and FAE1 (41) sequences have been used to identify six Arabidopsis ESTs that are putative condensing enzyme components of elongases (95). The FAE1, jojoba, and Arabidopsis cDNAs encode 56-60-kDa proteins, have membrane-spanning domains, and have two completely conserved Cys residues; one is potentially in the active site. Preliminary data indicate that some of the Arabidopsis ESTs are expressed in all organs except seed and root (J Todd, D Post-Beittenmiller \& J Jaworski, unpublished manuscript), a pattern that is consistent with the expected expression of an elongase involved in wax biosynthesis. In contrast, FAEl is expressed only in seeds, which is expected for a condensing enzyme involved in erucic acid biosynthesis (41).

\section{ENVIRONMENTAL FACTORS}

In addition to developmental controls, cuticular lipids are synthesized in response to environmental signals such as light intensity, photoperiod (101), humidity (91), chilling (77), and seasonal variation (34). One dramatic response of wax production to environmental stimuli is observed during tissue culture, where the relative humidity is high and wax production is low. When tissue-culture-grown plants are moved to a less humid environment (i.e. greenhouse or growth chamber), wax production is stimulated, and within days the plant synthesizes a complete and protective coating of wax. Brassica oleracea greenhouse-grown plants have 10-fold more wax than tissueculture-grown plants, and the decarbonylation pathway is stimulated preferentially (91). During the hardening-off period, more wax is produced on new leaves than on leaves that emerged during culturing, which suggests that rapidly expanding tissues have a greater capacity for wax production than nonexpanding tissues (92).

\section{CONCLUSIONS AND FUTURE PROSPECTS}

The ubiquitous presence of cuticular wax is testimony to its essential role in a plant's adaptation to an aerial environment. The fact that environmental factors influence wax composition and quantity is evidence that wax production is an actively regulated process. The diversity of wax components is evidence 
of the wealth of genes devoted to wax production. The differential regulation of cuticular wax production by tissue, organ, and developmental stage provides sophisticated controls on the expression of a complex biosynthetic pathway. The biosynthesis of plant cuticular wax has been studied for over three decades, with pioneering work done in several laboratories using elegant biochemical and genetic approaches. In spite of these efforts, we still know little about the factors that regulate the partitioning of fatty acid precursors and coordinately regulate the synthesis of waxes with the synthesis of cutin and glycerolipids. The cloning of wax biosynthetic genes has just begun, and it promises to open many new paths and bring exciting discoveries.

Any Annual Review chapter, as well as any article cited in an Annual Review chapter, may be purchased from the Annual Reviews Preprints and Reprints service. 1-800-347-8007; 415-259-5017; email: arpr@class.org

\section{Literature Cited}

1. Aarts MG, Keijzer CJ, Stiekema WJ, Pereira A. 1995. Molecular characterization of the CER1 gene of Arabidopsis involved in epicuticular wax biosynthesis and pollen fertility. Plant Cell 7:2115-27

2. Agrawal VP, Lessire R, Stumpf PK. 1984. Biosynthesis of very long chain fatty acids in microsomes from epidermal cells of $A l$ lium porrum L. Arch. Biochem. Biophys. 230:580-89

3. Agrawal VP, Stumpf PK. 1985. Characterization and solubilization of an acyl chain elongation system in microsomes of leek epidermal cells. Arch. Biochem. Biophys. 240:154-65

4. Avato P, Bianchi G, Pogna N. 1990. Chemosystematics of surface lipids from maize and some related species. Phytochemistry 29:1571-76

5. Avato P, Bianchi G, Salamini F. 1984. Genetic control of epicuticular lipids in maize (Zea mays L.). In Structure, Function and Metabolism of Plant Lipids, ed. PA Sigenthaler, W Eichenberg, pp. 179-98. Amsterdam: Elsevier/North Holland Biomed. Press

6. Avato P, Bianchi G, Salamini F. 1985. Absence of long chain aldehydes in the wax of the glossy 11 mutant of maize. Phytochemistry 24:1995-97

6a. Bergman DK, Dillwith JW, Zarrabi AA, Caddel JL, Berberet RC. 1991. Epicuticular lipids of alfalfa relative to its susceptibility to spotted alfalfa aphids (Homoptera aphididae). Environ. Entomol. 20:781-85

7. Bermadinger-Stabentheiner E. 1995. Physical injury, re-crystallization of wax tubes and artefacts: identifying some causes of structural alteration to spruce needle wax. New Phytol. 130:67-74

8. Bernhard WR, Thoma S, Botella J, Somerville CR. 1991. Isolation of a cDNA clone for spinach lipid transfer protein and evidence that the protein is synthesized by the secretory pathway. Plant Physiol. 95: 164-70

9. Deleted in proof

10. Bianchi G, Avato P, Salamini F. 1979. Glossy mutants of maize. IX. Chemistry of glossy4, glossy8, glossy 15 , and glossy 18 surface waxes. Heredity 42:391-95

11. Bianchi G, Avato P, Scarpa O, Murelli C, Audisio G, Rossini A. 1989. Composition and structure of maize epicuticular wax esters. Phytochemistry 28:165-71

12. Bianchi G, Murelli C, Ottaviano E. 1990. Maize pollen lipids. Phytochemistry 29: 739-44

13. Bianchi G, Tava A, Vlahov G, Pozzi N. 1994. Chemical structure of long-chain esters from "Sansa" olive oil. J. Am. Oil Chem. Soc. 71:365-69

14. Blée E. 1995. Oxygenated fatty acids and plant defenses. Inform 6:852-61

15. Breu V, Guerbette F, Kader J-C, Kannangara CG, Svensson B, von WettsteinKnowles PM. 1989. A 10-kD barley basic protein transfers phosphatidylcholine from liposomes to mitochondria. Carlsberg Res. Commun. 54:81-84

15a. Browse J, McCourt P, Somerville C. 1986. A mutant of Arabidopsis deficient in C18:3 and C16:3 leaf lipids. Plant Physiol. 81: 859-64 
16. Cahoon E, Lynch D. 1991. Analysis of glucocerebrosides of rye (Secale cerale $\mathrm{L}$. cv Puma) leaf and plasma membrane. Plant Physiol. 95:58-68

17. Cassagne C, Lessire R. 1978. Biosynthesis of saturated very long chain fatty acids by purified membrane fractions from leek epidermal cells. Arch. Biochem. Biophys. 191: 146-52

18. Cassagne C, Lessire R, Bessoule J-J, Moreau P. 1987. Plant elongases. In The Metabolism, Structure, and Function of Plant Lipids, ed. PK Stumpf, JB Mudd, WD Ness, pp. 481-88. New York: Plenum

19. Cassagne C, Lessire R, Bessoule J-J, Moreau P, Créach A, et al. 1994. Biosynthesis of very long chain fatty acids in higher plants. Prog. Lipid Res. 33:55-69

20. Cerioli S, Marocco A, Maddaloni M, Motto M, Salamini F. 1994. Early event in maize leaf epidermis formation as revealed by cell lineage studies. Development 120:2113-20

21. Cheesbrough TM, Kolattukudy PE. 1984. Alkane biosynthesis by decarbonylation of aldehydes catalyzed by a particulate preparation from Pisum sativum. Proc. Natl. Acad. Sci. USA 81:6613-17

22. Cinti DL, Cook L, Nagi MN, Suneja SK. 1992. The fatty acid chain elongation system of mammalian endoplasmic reticulum. Prog. Lipid Res. 31:1-51

23. Dennis MW, Kolattukudy PE. 1991. Alkane biosynthesis by decarbonylation of aldehyde catalyzed by a microsomal preparation from Botryococus braunii. Arch. Biochem. Biophys. 287:268-75

24. Dörmann P, Voelker T, Ohlrogge J. 1995. Cloning and expression in E. coli of a novel thioesterase from Arabidopsis thaliana specific for long chain acyl-acyl carrier proteins. Arch. Biochem. Biophys. Res. Commun. 316:612-18

25. Douady D, Grosbois M, Guerbette F, Kader J-C. 1986. Phospholipid transfer protein from maize seedlings is partly membrane-bound. Plant Science 45:151-56

26. Eigenbrode SD, Espelie KE. 1995. Effects of plant epicuticular lipids on insect herbivores. Annu. Rev. Entomol. 40:171-94

27. Evans M, Passas HJ, Poethig R. 1994. Heterochronic effects of glossy 15 mutations on the epidermal identity in maize. Development 120:1971-81

28. Evenson KJ, Post-Beittenmiller D. 1995. Fatty acid elongating activity in rapidlyexpanding leek epidermis. Plant Physiol. 109: 707-16

29. Fahleson J, Kraft M, Dunn P, PostBeittenmiller D. 1995. Towards mapbased cloning of CER7, a gene involved in epicuticular wax production in Arabidopsis thaliana. Presented at Biochem. Mol. Biol. Plant Fatty Acids Glycerolipids Symp., South Lake Tahoe, Calif.
30. Fleming AJ, Mandel T, Hofmann S, Sterk P, de Vries SC, Kuhlemeier C. 1992. Expression pattern of a tobacco lipid transfer protein gene within the shoot apex. Plant J. 2:855-62

31. Frentzen M. 1993. Acyl transferases and triacylglycerols. See Ref. 72a, pp. 195-230

32. Gausing K. 1994. Lipid transfer protein genes specifically expressed in barley leaves and coleoptiles. Planta 192:574-80

32a. Giese BN. 1976. Roles of the $c e r-j$ and cer-p loci in determining the epicuticular wax composition on barley seedling leaves. Hereditas 82:137-48

33. Gülz P-G. 1994. Epicuticular leaf waxes in the evolution of the plant kingdom. J. Plant Physiol. 143:453-64

34. Gülz P-G, Müller E. 1992. Seasonal variation in the composition of epicuticular waxes of Quercus robur leaves. Z. Naturforsch. 47:800-6

35. Gülz P-G, Prasad RBN, Müller E. 1991. Surface structure and chemical composition of epicuticular waxes during leaf development of Tilia tomentosa Moench. $Z$. Naturforsch. 46:743-49

36. Halfter U, Rashotte A, Jenks M, Eigenbrode S, Feldmann KA. 1995. Characterization and cloning of the Arabidopsis cer4 (eceriferum) mutant. Presented at Int. Conf. Arabidopsis Res., 6th, Madison, Wis.

37. Hannoufa A, Mcnevin J, Lemieux B. 1993. Epicuticular waxes of eceriferum mutants of Arabidopsis thaliana. Phytochemistry 33:851-55

38. Hannoufa A, Negruk V, Lemieux B. 1995. Molecular cloning of the CER3 gene of Arabidopsis thaliana. Presented at Int. Conf. Arabidopsis Res., 6th, Madison, Wis.

39. Hansen JD, Xu XJ, Xia YJ, Dietrich CR, Delledonne M, et al. 1995. Molecular cloning and characterization of plant cuticular wax genes. Presented at Maize Genet. Conf., 37th, Asilomar, Calif.

39a. Hlousek-Radojcic A, Imai H, Jaworski JG. 1995. Oleoyl-CoA is not an immediate substrate for fatty acid elongation in developing seeds of Brassica napus. Plant J. 8: 803-9

40. Ichihara K, Nakagawa M, Tanaka K. 1993. Acyl-CoA synthetase in maturing safflower seeds. Plant Cell Physiol. 34: 557-66

41. James DW Jr, Lim E, Keller J, Plooy I, Ralston E, Dooner HK. 1995. Directed tagging of the Arabidopsis FATTY ACID ELONGATION 1 (FAE1) gene with the maize transposon Activator. Plant Cell 7: 309-19

42. Jaworski JG, Post-Beittenmiller D, Ohlrogge JB. 1993. Acetyl-acyl carrier protein is not a major intermediate in fatty acid biosynthesis in spinach. Eur. J. Biochem. 213:981-87 
43. Jeffree C, Baker E, Holloway P. 1976. Origins of the fine structure of plant epicuticular waxes. In Microbiology of Aerial Plant Surfaces, ed. C Dickinson, T Preece, pp. 118-58. London: Academic

44. Jenks MA, Joly RJ, Peters PJ, Rich PJ, Axtell JD, Ashworth EN. 1994. Chemically induced cuticle mutation affecting epidermal conductance to water vapor and disease susceptibility in Sorghum bicolor (L.) Moench. Plant Physiol. 105:1239-45

45. Jenks MA, Rich PJ, Ashworth EN. 1994. Involvement of cork cells in the secretion of epicuticular wax filaments on Sorghum bicolor (L.) Moench. Int. J. Plant Sci. 155: 506-18

46. Jenks MA, Tuttle HA, Eigenbrode SD, Feldmann KA. 1995. Leaf epicuticular waxes of the eceriferum mutants in Arabidopsis. Plant Physiol. 108:369-77

46a. Jenks MA, Tuttle HA, Feldmann KA. 1996. Changes in epicuticular waxes on wildtype and eceriferium mutants in Arabidopsis during development. Phytochemistry. In press

47. Kalla R, Shimamoto K, Potter R, Nielsen PS, Linnestad C, Olsen O-A. 1994. The promoter of the barley aleurone-specific gene encoding a putative 7-kDa lipid transfer protein confers aleurone cell-specific expression in transgenic rice. Plant J. 6 : 849-60

48. Kolattukudy PE. 1968. Further evidence for an elongation-decarboxylation mechanism in the biosynthesis of paraffins in leaves. Plant Physiol. 43:375-83

49. Kolattukudy PE. 1971. Enzymatic synthesis of fatty alcohols in Brassica oleracea. Arch. Biochem. Biophys. 142:701-9

50. Kolattukudy PE. 1980. Biopolyester membranes of plants: cutin and suberin. Science 208:990-1000

51. Kolattukudy PE. 1980. Cutin, suberin, and waxes. In The Biochemistry of Plants, ed. PK Stumpf, EE Conn, 4:571-645. New York: Academic

52. Kolattukudy PE. 1987. Lipid-derived defensive polymers and waxes and their role in plant-microbe interaction. In The Biochemistry of Plants, ed. PK Stumpf, EE Conn, 9:291-314. New York: Academic

53. Koornneef M, Hanhart CJ, Thiel F. 1989. A genetic and phenotypic description of eceriferum (cer) mutants in Arabidopsis thaliana. J. Heredity 80:118-22

54. Kunst L, Taylor DC, Underhill EW. 1992. Fatty acid elongation in developing seeds of Arabidopsis thaliana. Plant Physiol. Biochem. 30:425-34

54a. Lassner MW, Lardizabal K, Metz JG. 1996. A jojoba $\beta$-ketoacyl-CoA synthase cDNA complements the canola fatty acid elongation mutation in transgenic plants. Plant Cell. In press
55. Lemieux B, Miquel M, Somerville CR, Browse J. 1990. Mutants of Arabidopsis with alterations in seed lipid fatty acid composition. Theor. Appl. Genet. 80:234-40

56. Lemieux B, Yang P, Hannoufa A, Negruk V, Subramanian M, Deng M-d. 1995. Molecular genetics of wax biosynthesis in Arabidopsis. Presented at Int. Conf. Arabidopsis Res., 6th, Madison, Wis.

57. Lessire R, Bessoule J-J, Cassagne C. 1989. Involvement of a $\beta$-ketoacyl-CoA intermediate in acyl-CoA elongation by an acyl-CoA elongase purified from leek epidermal cells. Biochim. Biophys. Acta 1006:35-40

58. Lessire R, Cassagne C. 1979. Long chain fatty acid CoA-activation by microsomes from Allium porrum epidermal cells. Plant Sci. Lett. 16:31-39

59. Lessire R, Hartmann-Bouillon MA, Cassagne C. 1982. Very long chain fatty acids: occurrence and biosynthesis in membrane fractions from etiolated maize coleoptiles. Phytochemistry 21:55-59

60. Lessire R, Stumpf PK. 1982. Nature of the fatty acid synthetase systems in parenchymal and epidermal cells of Allium porrum L. leaves. Plant Physiol. 73:614-18

61. Liu D, Post-Beittenmiller D. 1995. Discovery of an epidermal stearoyl-acyl carrier protein thioesterase: its potential role in wax biosynthesis. J. Biol. Chem. 270: 16962-69

62. Lundqvist U, von Wettstein-Knowles PM. 1982. Dominant mutations at cer-yy change barley spike wax into leaf blade wax. Carlsberg Res. Commun. 47:29-43

63. Lundqvist U, von Wettstein-Knowles PM. 1983. Phenotypic diversity of barley spike waxes resulting from mutations at locus cer-n. Carlsberg Res. Commun. 48:321-44

64. Maddaloni M, Bossinger G, DiFonzo N, Motto M, Salamini F, Bianchi A. 1990. Unstable alleles of the GLOSSY-1 locus of maize show a light-dependent variation in the pattern of somatic reversion. Maydica 35:409-20

65. Maddaloni M, Albano M, Motto M, Salamini F. 1991. Unstable alleles generated at various glossy loci. Maize Genet. Coop Newsl. 65:25-26

66. Madrid S, Weber E, von WettsteinKnowles PM. 1990. Characterization and targeting of a barley phosphatidylcholine transfer protein (LTP). Presented at Plant Lipid Biochem. Struct. Util., Wye College, Kent, Engl.

67. Madrid SM. 1991. The barley lipid transfer protein is targeted into the lumen of the endoplasmic reticulum. Plant Physiol. Biochem. 29:695-703

68. Meusel I, Leistner E, Barthlott W. 1994. Chemistry and micromorphology of compound epicuticular wax crystalloids (Strelitzia type). Plant Syst. Evol. 193:115-23 
69. Mikkelsen JD. 1979. Structure and biosynthesis of $\beta$-diketones in barley spike epicuticular wax. Carlsberg Res. Commun. 44: 133-47

70. Mikkelsen JD, von Wettstein-Knowles PM. 1978. Biosynthesis of $\beta$-diketones and hydrocarbons in barley spike epicuticular wax. Arch. Biochem. Biophys. 1288: 172-81

71. Deleted in proof

72. Deleted in proof

72a. Moore TS, ed. 1993. Lipid Metabolism in Plants. Boca Raton, FL: CRC Press

73. Moose SP, Sisco PH. 1995. The maize homeotic gene GLOSSY15 is a member of the APETALA2 gene family. J. Cell. Biochem. 21A:458

74. Deleted in proof

75. Negruk V, Yang $\mathrm{P}$, Subramanian $\mathrm{M}$, McNevin JP, Lemieux B. 1995. A novel protein regulates very long chain fatty acid elongation in Arabidopsis thaliana. Presented at Int. Conf. Arabidopsis Res., 6th, Madison, Wis.

76. Newman T, de Bruijn FJ, Green P, Keegstra K, Kende H, et al. 1994. Genes galore: a summary of methods for accessing results from large-scale partial sequencing of anonymous Arabidopsis cDNA clones. Plant Physiol. 106:1241-55

77. Nordby HE, McDonald RE. 1991. Relationship of epicuticular wax composition of grapefruit to chilling injury. J. Agric. Food Chem. 39:957-62

78. Ohlrogge JB, Jaworski JG, PostBeittenmiller D. 1993. De novo fatty acid biosynthesis. See Ref. 72a, pp. 3-32

79. Ohlrogge JB, Shine WE, Stumpf PK. 1978. Fat metabolism in higher plants: characterization of plant acyl-ACP and acyl-CoA hydrolases. Arch. Biochem. Biophys. 189: 382-91

80. Pollard M, McKeon T, Gupta L, Stumpf P. 1979. Studies on biosynthesis of waxes by developing jojoba seed. II. The demonstration of wax biosynthesis by cell-free homogenates. Lipids 14:651-62

81. Post-Beittenmiller D, Evenson K, Liu D, Jaworski J. 1994. Examination of the terminal steps of fatty acid biosynthesis in leek epidermis and their relevance to wax biosynthesis. Presented at Int. Meet. Plant Lipids, 11th, Paris

82. Preuss D, Lemieux B, Yen G, Davis RW. 1993. A conditional sterile mutation eliminates surface components from Arabidopsis pollen and disrupts cell signaling during fertilization. Genes Dev. 7:974-85

83. Pyee J, Kolattukudy PE. 1995. The gene for the major cuticular wax-associated protein and three homologous genes from broccoli (Brassica oleracea) and their expression patterns. Plant J. 7:49-59

84. Pyee J, Yu H, Kolattukudy PE. 1994. Iden- tification of a lipid transfer protein as the major protein in the surface wax of broccoli (Brassica oleracea) leaves. Arch. Biochem. Biophys. 311:460-68

85. Reed JR, Vanderwel D, Choi S, Pomonis JG, Reitz RC, Blomquist GJ. 1994. Unusual mechanism of hydrocarbon formation in the housefly: cytochrome P450 converts aldehyde to the sex pheromone component (Z)-9-tricosene and $\mathrm{CO}_{2}$. Proc. Natl. Acad. Sci. USA 91:10000-4

86. Rickers J, Spener F, Kader J-C. 1985. A phospholipid transfer protein that binds long-chain fatty acids. FEBS Lett. 180: 29-32

87. Schnable PS, Stinard PS, Wen T-J, Heinen S, Weber D, et al. 1994. The genetics of cuticular wax biosynthesis. Maydica 39: 279-87

88. Shimakata T, Stumpf PK. 1982. Isolation and function of spinach leaf $\beta$-ketoacyl[acyl-carrier-protein] synthases. Proc. Natl. Acad. Sci. USA 79:5808-12

89. Sossountzov L, Ruiz-Avila L, Vignols F, Jolliot A, Arondel V, et al. 1991. Spatial and temporal expression of a maize lipid transfer protein gene. Plant Cell 3:923-33

90. Sterk P, Booij H, Schellekens GA, Van Kammen A, De Vries SC. 1991. Cellspecific expression of the carrot EP2 lipid transfer protein gene. Plant Cell 3:907-21

91. Sutter E. 1984. Chemical composition of epicuticular wax in cabbage plants grown in vitro. Can. J. Bot. 62:74-77

92. Sutter E, Langhans RW. 1982. Formation of epicuticular wax and its effect on water loss in cabbage plants regenerated from shoot-tip culture. Can. J. Bot. 60:2896-902

93. Deleted in proof

94. Thoma S, Kaneko Y, Somerville CR. 1993. A non-specific lipid transfer protein from Arabidopsis is a cell wall protein. Plant J. 3:427-36

95. Todd J, Post-Beittenmiller D, Jaworski J. 1995. Characterization and manipulation of fatty acid elongase genes in Arabidopsis. Presented at Biochem. Mol. Biol. Plant Fatty Acids Glycerolipids Symp., South Lake Tahoe, Calif.

96. Vogel JM, Freeling M. 1993. Molecular genetic analysis of maize glossy genes: role in epicuticular wax production. Presented at Keystone Symp. Mol. Cell. Biol., Keystone, Colo.

97. von Wettstein-Knowles PM. 1979. Genetics and biosynthesis of plant epicuticular waxes. Advances in Biochem and Physiol of Plant Lipids, ed. L-Åppelqvist, C Liljenberg, pp. 1-26. Amsterdam: Elsevier/North Holland Biomed. Press

98. von Wettstein-Knowles PM. 1982. Elongases and epicuticular wax biosynthesis. Physiol. Vég. 20:797-809

99. von Wettstein-Knowles PM. 1987. Genes, 
elongases and associated enzyme systems in epicuticular wax synthesis. In The Metabolism, Structure, and Function of Plant Lipids, ed. PK Stumpf, JB Mudd, WD Ness, pp. 489-98. New York: Plenum

100. von Wettstein-Knowles PM. 1995. Biosynthesis and genetics of waxes. In Waxes: Chemistry, Molecular Biology and Functions, ed. RJ Hamilton, 6:91-130. Allowry, Ayr, Scotland: Oily Press

100a. von Wettstein-Knowles PM. 1993. Waxes, cutin, and suberin. See Ref. 72a, pp. $127-66$

101.von Wettstein-Knowles PM, Avato P, Mikkelsen JD. 1980. Light promotes synthesis of the very long fatty acyl chains in maize wax. In Biogenesis and Function of Plant Lipids, ed. P Mazliak, P Benveniste, C Costes, R Douce, pp. 271-74. Amsterdam: Elsevier/North-Holland Biomed. Press

102. von Wettstein-Knowles PM, Søgaard B. 1980. The cer-cqu region in barley: gene cluster or multifunctional gene. Carlsberg Res. Commun. 45:125-41

103. von Wettstein-Knowles PM, Søgaard B. 1981. Genetic evidence that cer-cqu is a a cluster-gene. Barley Genetics IV: Proc. 4th Int. Barley Genet. Symp., pp. 625-30. Edinburgh: Edinburgh Univ. Press

104. Deleted in proof

105. Walton TJ. 1990. Waxes, cutin and suberin. In Methods in Plant Biochemistry: Lipids, Membranes and Aspects of Photo- biology, ed. JL Harwood, JR Bowyer, 4:105-58. San Diego: Academic

106. Watanabe S, Yamada M. 1986. Purification and characterization of a non-specific lipid transfer protein from germinated castor bean endosperms which transfers phospholipids and galactolipids. Biochim. Biophys. Acta 876:116-23

107. Whitfield HV, Murphy DJ, Hills MJ. 1993. Sub-cellular localization of fatty-acid elongase in developing seeds of Lunaria annua and Brassica napus. Phytochemistry 32: 255-58

108. Xia Y, Xu X, Hansen JD, Dietrich CR, Delledonne M, et al. 1995. Molecularcloning and characterization of cuticular wax genes. Presented at Int. Conf. Arabidopsis Res., 6th, Madison, Wis.

109. Xu XJ, Xia YJ, Heinen S, Hansen J, Stinard PS, et al. 1994. Molecular cloning of $\mathrm{cu}$ ticular wax genes from maize and Arabidopsis. Presented at Int. Congr. Plant Mol. Biol., 4th, Amsterdam

110. Yamada M. 1992. Lipid transfer proteins in plants and microorganisms. Plant Cell Physiol. 33:1-6

111. Yang G, Espelie KE, Todd JW, Culbreath AK, Pittman RN, Demski JW. 1993. Cuticular lipids from wild and cultivated peanuts and the relative resistance of these peanut species to fall armyworm and thrips. J. Agr. Food Chem. 41:814-18 